\title{
Neuroprotective effects of the ethanol extract of Salvia miltiorrhiza in Northern Vietnam against amyloid beta $25-35$-induced learning and memory impairment in vivo and cytotoxicity in vitro
}

\author{
Thi Loan Tran ${ }^{1 *}$, \\ Thanh Hai Nguyen ${ }^{2}$, \\ Nguyet Hang Thi Pham³, \\ Thien Thuong Phuong ${ }^{4}$, \\ Thi Thanh Nguyen ${ }^{5}$, \\ Hong Linh Tran ${ }^{5}$, \\ Thi Vui Dao ${ }^{*}$
}

\footnotetext{
1 Department of Pharmacy, Thai Nguyen Central Hospital, 479 Luong Ngoc Quyen, Thai Nguyen, Vietnam

2 Department of Clinical Pharmacy, Hanoi University of Pharmacy, 13-15 Le Thanh Tong, Hoan Kiem, Hanoi, Vietnam

${ }^{3}$ Department of Pharmacology and Biochemistry, National Institute of Medicinal Materials, 3B Quang Trung, Hoan Kiem, Hanoi, Vietnam

${ }^{4}$ Biotechnology Division, Vietnam - Korea Institute of Science and Technology, 113 Tran Duy Hung, Cau Giay, Hanoi, Vietnam 5 Department of Pharmacology, Hanoi University of Pharmacy, 13-15 Le Thanh Tong, Hoan Kiem, Hanoi, Vietnam
}

\section{*Corresponding author:}

Thi Loan Tran

tranloandhd87@gmail.com

Thi Vui Dao

daothivuidl@yahoo.com

Keywords:

Alzheimer's disease;

Amyloid beta25-35; Cytotoxicity;

Learning and memory;

Salvia miltiorrhiza

https://www.pharmacy.mahidol.ac.th/journal/ (c) Faculty of Pharmacy, Mahidol University (Thailand) 2021

\begin{abstract}
Salvia miltiorrhiza is a highly valued plant of traditional Asian medicine. The previous studies have reported that the active components of radix Salvia miltiorrhiza (RSM) have multiple potentials related to Alzheimer's disease. However, the influence of RSM ethanol extract (ETE) in the mouse model of learning and memory impairment and in vitro cytotoxicity has not been studied extensively. This study was designed to investigate the effects and mechanism of Vietnamese RSM ethanol extract against amyloid beta $25-35$ (A $\beta_{25-35}$ )-induced the learning and memory impairment in vivo and toxicity examined on NG108-15 cells. Our results showed that ETE at doses of 400,600 and $1200 \mathrm{mg} / \mathrm{kg}$ significantly attenuated impairment of spatial memory in the Y-maze test. However, the improving long-term memory effect in the passive avoidance test was only observed at doses of 600 and $1200 \mathrm{mg} / \mathrm{kg}$. Furthermore, these two doses of ETE also prevented the increase of malondialdehyde (MDA) levels in brain tissue homogenates in mice. In vitro, the treatment at $2.0 \mu \mathrm{g} / \mathrm{ml}$ of ETE inhibited the $A \beta_{25-35}$-induced cytotoxicity. This is the first study to indicate that ETE has the protective potential against $A \beta_{25-35}$-induced neurotoxicity by regulating oxidative stress in the brain of mice. These results suggest that Salvia miltiorrhiza may be a promising candidate for the treatment of Alzheimer's disease.
\end{abstract}

\section{INTRODUCTION}

Alzheimer's disease (AD) is the most common progressive neurodegenerative disorder ${ }^{1}$. It is characterized by the gradual degeneration and loss of neurons in the brain, which correlate with the accumulation of extracellular plaques of amyloid- $\beta$ peptide $(\mathrm{A} \beta)$ aggregates and intracellular neurofibrillary tangles. $A \beta$, the major component of senile plaques, could have a causal role in the development and progress of $\mathrm{AD}^{2}$. $\mathrm{A} \beta_{25-35}$ fragment, the biologically active region of $A \beta$ protein disturbed the cellular integrity and function ${ }^{3}$. The toxicity of $A \beta_{25-35}$ injection in rodents induced memory deficits, oxidative stress. Additionally, previous studies showed that $A \beta_{25-35}$ accumulation was associated with cellular toxicity. Thus, $A \beta_{25-35}$ is a useful tool for establishing $\mathrm{AD}$ models and investigating the mechanisms involved in $\mathrm{AD}$ pathogenesis ${ }^{4}$.

The pharmacological treatment used to improve the cognitive functions of patients includes two types of drugs, the 
acetylcholinesterase inhibitors and the NMDA receptor antagonist. Both types of drugs cannot stop progressive neuritic dystrophy, thus limiting their clinical efficacy ${ }^{5}$. Therefore, alternative agents to treat AD are necessary. Many herbal treatments have been demonstrated beneficial effects in different AD-related models as well as in clinical trials ${ }^{6}$.

Salvia miltiorrhiza is a well-known medicinal plant in the Lamiaceae family for the treatment of cardiovascular and cerebrovascular diseases in traditional Asian medicine $^{7}$. The previous studies have indicated its potential therapeutics in the treatment of neurodegenerative disorders. Chemically, the active constituents of RSM can be classified into two groups. The lipid-soluble components are mainly tanshinones such as tanshinone I, tanshinone IIA, dihydrotanshinone I and cryptotanshinone, which belong to a group of diterpenes. The water-soluble parts are phenolic compounds consisting of salvianolic acid B, danshensu, protocatechuic aldehyde. Tanshinone IIA and salvianolic acid B were selected as major markers to check the quality of $\mathrm{RSM}^{8,9}$. Recently, researchers have addressed that these components have multiple neuroprotective potentials that are relevant to AD such as anti$\mathrm{A} \beta$, antioxidant ${ }^{5}$. However, these studies focused on the assessment of the activity of individual chemical compounds rather than the crude extracts of RSM. In particular, it has not yet been established whether ethanol extract can improve toxicity induced by $\mathrm{A} \beta_{25-35}$.

The main aim of this study was to assess the effects of Vietnamese RSM ethanol extract on the learning and memory impairment induced by i.c.v. injection of $A \beta_{25-35}$ in vivo. To examine its mechanisms mediated neuroprotection, we measured the levels of malondialdehyde (MDA) in the brain tissue homogenate in the injection of $A \beta_{25-35}$-induced mouse model and $A \beta_{25-35}$-treated NG108-15 cell cytotoxicity.

\section{MATERIALS AND METHODS}

\subsection{Materials}

\subsubsection{Plant material}

RSM was collected in December 2017

from Tan Lap, Moc Chau district, Son La province, Vietnam. It was authenticated by Prof. Loc Phan Ke, Faculty of Biology, Hanoi National University. The voucher specimen (No HNU
022613) has been deposited at the herbarium of National University of Hanoi, Vietnam.

\subsubsection{Preparation of RSM ethanol extract}

The dried powder of RSM $(9 \mathrm{~kg}$ ) was extracted with 50 liters of absolute ethanol by the percolation method. After 10 days, the extract was collected with a flow of 1.5 liters per hour and the volume of solvent equivalent to that of extract collected was added until the extract was light in color. Then, the extract was filtered and evaporated by using a rotary evaporator under reduced pressure and freeze-dried to obtain ETE $(1312.9 \mathrm{~g})$.

\subsubsection{High performance liquid chromatography (HPLC) analysis of ETE}

The contents of main components including tanshinone IIA and salvianolic acid B were measured by HPLC. The separation was carried out in triplicate in a C-18 column $(5 \mu \mathrm{m}$, $4.6 \times 250 \mathrm{~mm}$ ). ETE was dissolved in absolute methanol to measure tanshinone IIA or in $75 \%$ methanol $(\mathrm{v} / \mathrm{v})$ to measure salvianolic acid $\mathrm{B}$. Tanshinone IIA and salvianolic acid B (53.2 $\mu \mathrm{g} / \mathrm{ml}$ and $499 \mu \mathrm{g} / \mathrm{ml}$ in methanol, respectively) were used as reference standard for the HPLC analysis of ETE according to Vietnamese Pharmacopoeia ${ }^{10}$. The contents of tanshinone IIA and salvianolic acid B in ETE were calculated from relevant peak areas with the external standard method.

\subsection{Chemicals}

$\mathrm{A} \beta_{25-35}$ fragment $\mathrm{A} 4559$, tetramethoxypropane, thiobarbituric acid, [3-(4,5-dimethylthiazol-2,5diphenyltetrazolium bromide] (MTT), donepezil, chloral hydrate were purchased from Sigma Aldrich. Solvents for extraction and fractionation were of industrial grade purchased from a licensed chemical company in Hanoi, Vietnam.

\subsection{Animals}

Male Swiss mice (7-8 weeks old, weighing $32 \pm 2 \mathrm{~g}$ ) were provided by the National Institute of Hygiene and Epidemiology (Hanoi, Vietnam). Animals were used and processed according to the suggested ethical guidelines for the National Institutes of Health Guide for the Care and Use of Laboratory Animals. They were housed in a controlled room $\left(25 \pm 2{ }^{\circ} \mathrm{C}\right.$; humidity of 55-60\%) under a reversed 12/12 hours light/dark cycles (light on at 8:00 p.m.). 


\subsection{Cell culture}

NG108-15 neuroblastoma X glioma cells were supported by Associate Professor Michihisa Tohda, Sugitani Campus, University of Toyama, Japan. Cells were routinely cultured in a mixture of Dulbecco's modified Eagle's medium (DMEM) containing $4 \%$ fetal bovine serum, $100 \mu \mathrm{M}$ hypoxanthine, $1 \mu \mathrm{M}$ aminopterin, $16 \mu \mathrm{M}$ thymidine and $1 \mu \mathrm{g} / \mathrm{ml}$ minomycin under a humidified atmosphere of $5 \% \mathrm{CO}_{2}-95 \%$ air at $37^{\circ} \mathrm{C}$. Cells were seeded into 96-well microplates at a density of $8 \mathrm{x}$ $10^{3}$ cells per well. All experiments were carried out 24 hours after the cells were seeded.

\subsection{In vivo experiments}

\subsubsection{Experimental protocol}

Mice were randomly divided into 6 groups (11 animals/group). Control (I); $A \beta_{25-35}$ (II); $\mathrm{A} \beta_{25-35}+5 \mathrm{mg} / \mathrm{kg}$ Donepezil (III); $\mathrm{A} \beta_{25-35}+$ $400 \mathrm{mg} / \mathrm{kg}$ ethanol extract (IV); $\mathrm{A} \beta_{25-35}+600$ $\mathrm{mg} / \mathrm{kg}$ ethanol extract $(\mathrm{V}) ; \mathrm{A} \beta_{25-35}+1200 \mathrm{mg} / \mathrm{kg}$ ethanol extract (VI). Mice in the control and $\mathrm{A} \beta_{25-35}$ group were administrated sodium carboxymethylcellulose 5\% (NaCMC). Animals in the remaining groups were treated with ETE at the doses of 400,600 and $1200 \mathrm{mg} / \mathrm{kg}$ or donepezil (DNZ) at $5 \mathrm{mg} / \mathrm{kg}$. On the fourteenth day, mice were i.c.v. injected with sterile water or $\mathrm{A} \beta_{25-35}$.

In there, $A \beta_{25-35}$ was dissolved in sterile bidistilled water at a concentration of $1 \mathrm{mM}$ and incubated for 4 days at $37^{\circ} \mathrm{C}$ to cause peptide aggregation before using. Mice were anesthetized with $3.5 \%$ chloral hydrate before placed in a stereotaxic instrument and implanted with a $28-G$ stainless-steel needle into the right lateral ventricular $(0.2 \mathrm{~mm}$ posterior, $1.0 \mathrm{~mm}$ lateral and $2.5 \mathrm{~mm}$ ventral to bregma) based on the mouse brain atlas ${ }^{11}$. After that, a volume of 9 $\mu 1$ aggregated $A \beta_{25-35}$ (equivalent to $9 \mathrm{nmol}$ per mouse) was given into the mouse brain through i.c.v. injection by a micro-probe as previously described $^{4,12}$. Mice in the control group were received an equal volume of vehicle. The Experimental schedule is detailed in Figure 1.

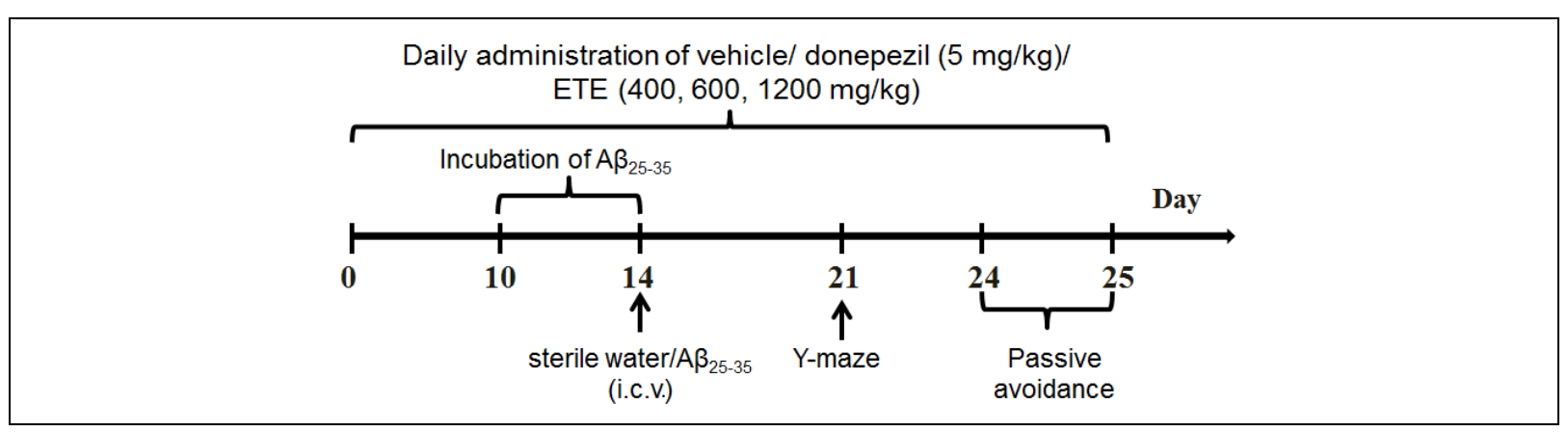

Figure 1. Experimental schedule.

\subsubsection{Behavioral examination}

The Y-maze is used as a measure of immediate spatial working memory, a form of short-term memory ${ }^{4}$ Each mouse was placed at the end of one arm in a Y-maze and allowed to explore freely through the maze during a single 8-min session 7 days after $A \beta_{25-35}$ peptide or sterile water injection. The percentage of alternation was calculated according to the following equation. Alternation $(\%)=[$ (number of perfect alternations $) /($ total arm entries -2$)] \times 100$.

The passive avoidance test was carried out in identical illuminated and non-illuminated boxes separated by a guillotine door, as previously described $^{13}$. For the acquisition phase, mice were initially placed in the illuminated compartment; the door between the two compartments was opened $30 \mathrm{~s}$ later. When the mice entered the non-illuminated compartment, an electrical foot shock (0.30 mA) for $3 \mathrm{~s}$ was delivered through the stainless steel rods. 24 Hours after the acquisition phase, the test phase was implemented similarly, but without giving the aversive stimulus to measure the latency time (latency to enter the dark compartment). The maximum latency time was $300 \mathrm{~s}$.

\subsubsection{Measurement of lipid peroxidation level}

MDA, a marker of lipid peroxidation, was evaluated by using the thiobarbituric acid reaction (TBAR) method as described by Wasowicz ${ }^{14}$. The tissues containing hippocampus and cortex were homogenized in ice-cold phosphate buffer. The homogenate was centrifuged at $10,000 \mathrm{rpm}$ and $0^{\circ} \mathrm{C}$ in 15 minutes, and the supernatant was used to determine MDA levels. $1 \mathrm{ml}$ TBAR reagent was added to a 150 $\mu \mathrm{l}$ aliquot of test supernatant and heated for 60 
minutes at $100^{\circ} \mathrm{C}$. The formed colored adduct was extracted by n-butanol and then measured spectrophotometrically at $532 \mathrm{~nm}$. The result was expressed as MDA equivalent (nmol $\mathrm{MDA} / \mathrm{g}$ tissue), using freshly prepared tetramethoxypropane as standard.

\subsection{In vitro experiments}

$\mathrm{A} \beta_{25-35}$ was incubated at $37^{\circ} \mathrm{C}$ for 48 hours before using and directly added to the cultured medium to achieve a final concentration of $20 \mu \mathrm{M}$. The extract was dissolved in dimethylsulfoxide with a concentration of 100 $\mathrm{mg} / \mathrm{ml}$ and diluted to different concentrations. To assess the neuroprotective effect of ethanol extract, cells were pre-treated with the samples for 2 hours and then exposed to $A \beta_{25-35}$ for 48 hours.

Cell viability was determined by [3-(4,5dimethylthiazol-2,5-diphenyltetrazolium bromide] (MTT) assay ${ }^{6}$. The assay based on the ability of a mitochondria dehydrogenase enzyme from viable cells to cleave the tetrazolium rings of the pale yellow MTT and form dark blue formazan crystals. After 48 hours of incubation period with $\mathrm{A} \beta_{25-35}$, MTT was added to each well and incubated for 4 hours at $37^{\circ} \mathrm{C}$. At the end of treatment, the medium was removed, $100 \mu$ of dimethyl sulfoxide was added to each well to dissolve crystals. The color was quantified by using an ELISA reader at 490 $\mathrm{nm}$. The optical density of formazan indicated
$100 \%$ viability in the control cells.

\subsection{Statistical analysis}

All data were calculated using Excel (Microsoft, USA), SPSS 20.0 program. The data on alternation percentages, biochemical and in vitro tests are expressed as mean \pm SEM. Two-group comparisons were made using the Student's t-test. When compared more than two groups, data were analyzed using one-way ANOVA followed by LSD or Dunnett's T3 post hoc. The latency times in the passive avoidance test are expressed as median (interquartile range) because the upper cut off time was set. They were analyzed using a Kruskal-Wallis nonparametric ANOVA and followed by the Dunn's multiple comparison test. The level of statistical significance was $p<0.05$.

\section{RESULTS}

\subsection{Determination of the chemical components from ETE}

HPLC analysis of RSM ethanol extract confirmed the dominant presence of tanshinone IIA and salvianolic acid B in the ETE samples. Using the external standard method, our HPLC analysis showed that ETE contained 3.10\% tanshinone IIA and $11.63 \%$ salvianolic acid B (Figure 2).

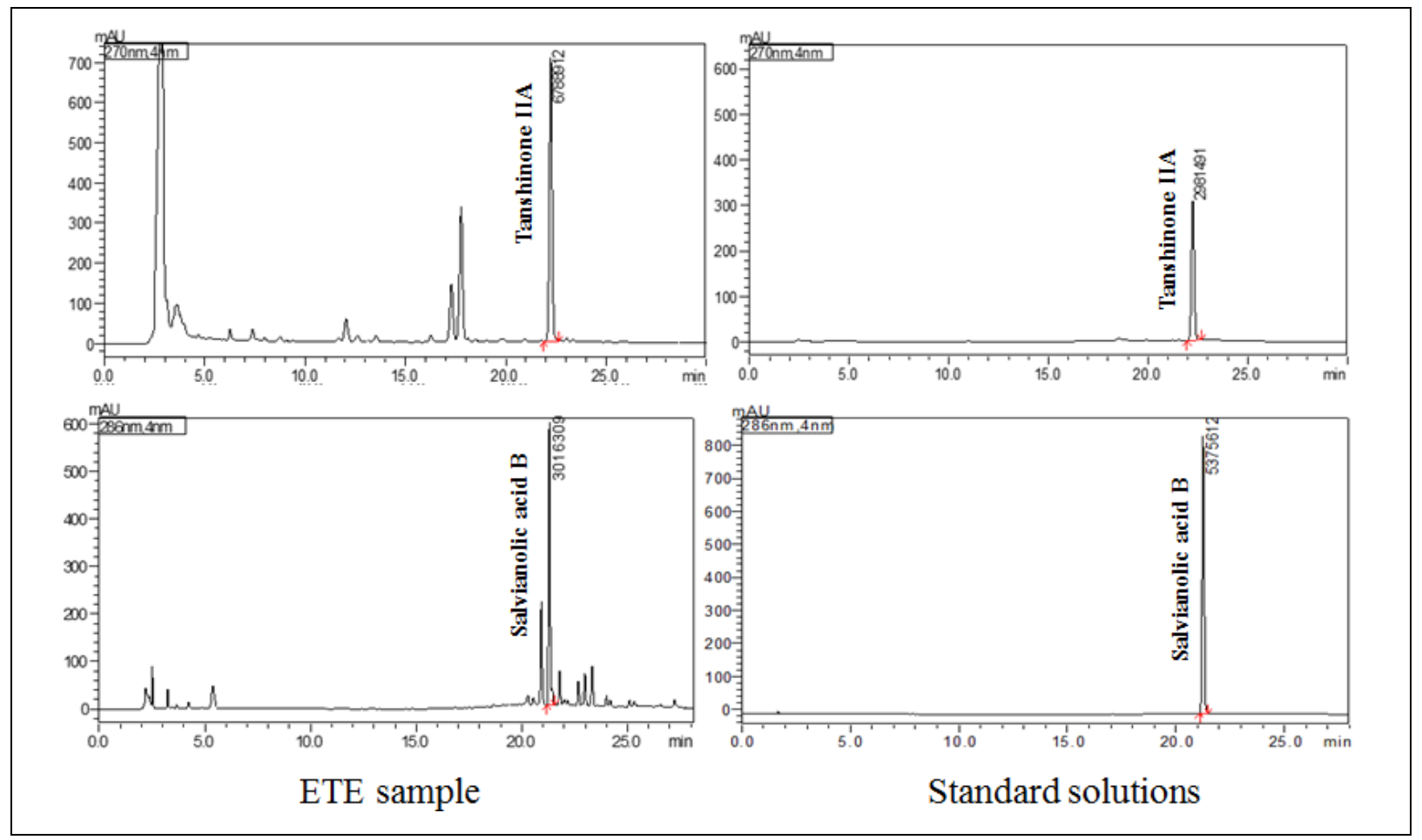

Figure 2. HPLC analysis of tanshinone IIA and salvianolic acid B in ETE. 


\subsection{Effects of ETE against the $A \beta_{25-35}$-induced the learning and memory impairment}

The neuroprotective effects of ETE through the behavioral parameters recorded in the Y-maze and passive avoidance tests in Figure 3 . Mice were orally treated with the extract (400, 600 or $1200 \mathrm{mg} / \mathrm{kg})$, donepezil $(5 \mathrm{mg} / \mathrm{kg})$ or vehicle once daily for 25 consecutive days.

The Y-maze test was examined 7 days after i.c.v. injection of $A \beta_{25-35}$. The mean spontaneous alternation in the $A \beta_{25-35}$ group was $51.09 \pm 1.35 \%$, while that in the control group was $70.21 \pm 1.32 \%$. The results showed that $\mathrm{A} \beta_{25-35}$ exposure decreased (around 27\%) this parameter, compared with the control group $(p<0.001)$. Mice treated with ETE $(400,600$ and $1200 \mathrm{mg} / \mathrm{kg}$ ) had higher spontaneous alternations (around 22, 34 and 28\%, respectively) than mice in the $\mathrm{A} \beta_{25-35}$ group $(p<0.001)$. Donepezil, a standard anti-Alzheimer drug also significantly increased spontaneous alternation by around $33 \%$ compared with the $\mathrm{A} \beta_{25-35}$ group $(p<0.001)$. Locomotion activity, estimated by the number of arm entries was similar in all experimental groups (Figure 3A, B).
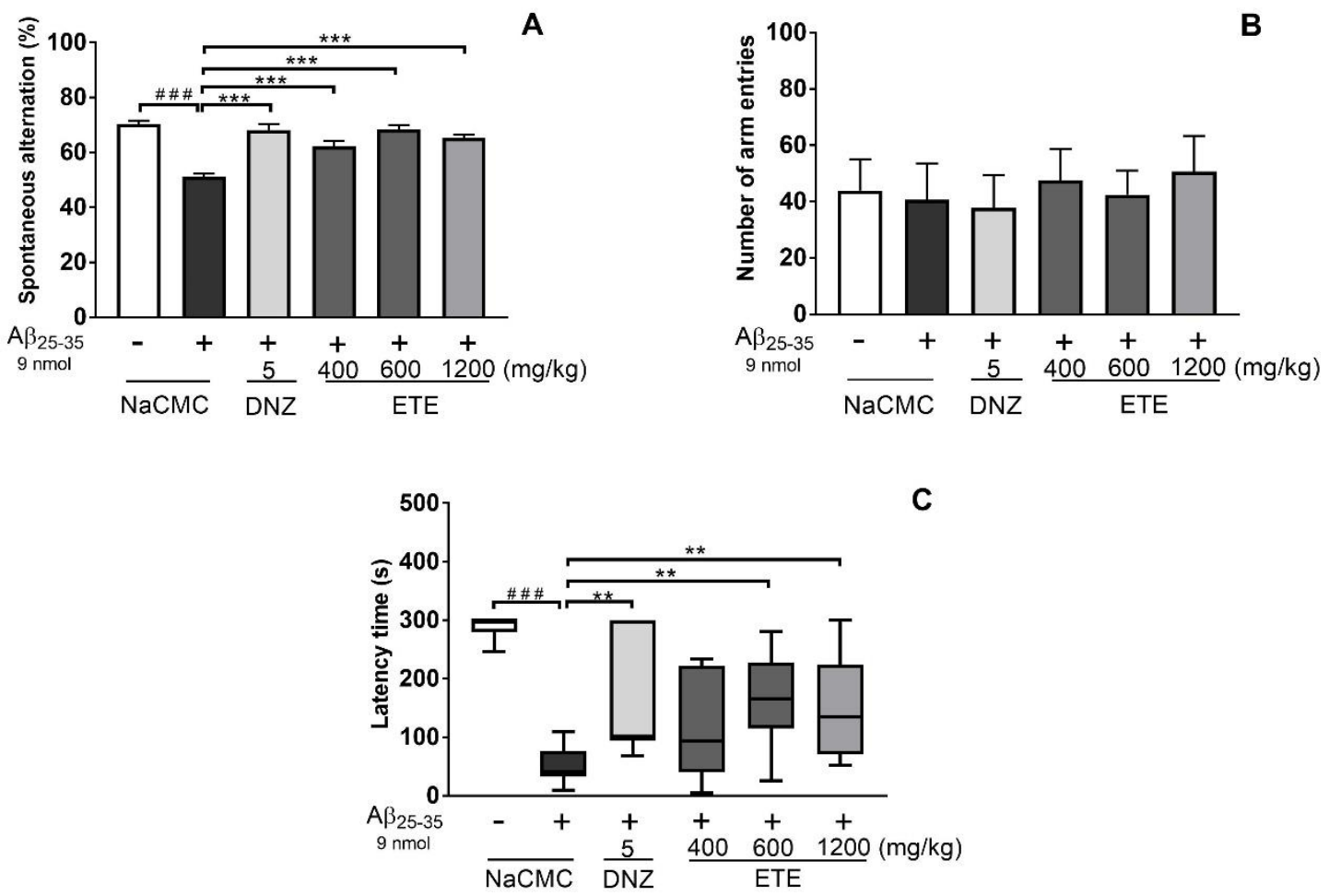

Figure 3. Effects of ETE on the learning and memory impairment induced by A $\beta_{25-35}$. (A) spontaneous alternation, (B) number of arm entries in the Y-maze and (C) latency time in the passive avoidance test. The data are represented in (A, B) as mean \pm S.E.M and in (C) as median (interquartile range $25-75 \%$ ). ${ }^{\# \#} p<0.001$ versus NaCMC-treated, distilled water-injected mice; ${ }^{* *} p<0.01,{ }^{* * *} p<0.001$ versus NaCMC-treated, $\mathrm{A} \beta 25-35$-injected mice. $\mathrm{N}=11$ per group.

In the test phase of the passive avoidance task, injection of $A \beta_{25-35}$ significantly decreased in latency time (around 86\%) compared with the control group $(p<0.001)$. In comparison with the $\mathrm{A} \beta_{25-35}$ group, ETE significantly prevented this reduction (around 297 and 224\% with $p=0.006$ and 0.007 , respectively) with the doses of 600 and $1200 \mathrm{mg} / \mathrm{kg}$, but ETE at the dose of 400 $\mathrm{mg} / \mathrm{kg}$ did not significantly affect the latency time $(p=0.181)$. In addition, this parameter in the donepezil group also showed a $143 \%$ increase compared with the $A \beta_{25-35}$ group $(p=0.001)$ (Figure 3C).

The results of behavioral tests demonstrated that, following oral administration, ETE at the doses of 600 and $1200 \mathrm{mg} / \mathrm{kg}$ was able to improve learning and memory impairment both in Y maze and passive avoidance tests. However, ETE at the dose of $400 \mathrm{mg} / \mathrm{kg}$ only could significantly increase the spontaneous alternations in the $\mathrm{Y}$ maze test. Therefore, the ETE doses of 600 and $1200 \mathrm{mg} / \mathrm{kg}$ were used for in vivo experiments investigated the mechanism of the samples. 


\subsection{Effects of ETE on MDA levels in the brain tissue homogenates}

Figure 4 illustrates the effects of samples on the levels of MDA in the tissue containing hippocampus and cortex 14 days after the $A \beta_{25-35}$ injection. The mean level of MDA in $A \beta_{25-35}$ group was $13.51 \pm 0.35 \mathrm{nmol} / \mathrm{g}$ tissue, while that in the control group was $6.89 \pm 0.33 \mathrm{nmol} / \mathrm{g}$ tissue. It showed that $A \beta_{25-35}$ increased by around 96\% MDA level significantly $(p<0.001)$. In comparison with the $A \beta_{25-35}$ group, both doses of ETE significantly prevented the increase of MDA levels (around 22 and 19\% and $p<0.001$ ). The decreased parameter were also recorded in the brain tissues of mice treated with donepezil (around $17 \%$ and $p<0.001$ ) compared to that of mice in the $A \beta_{25-35}$ group.

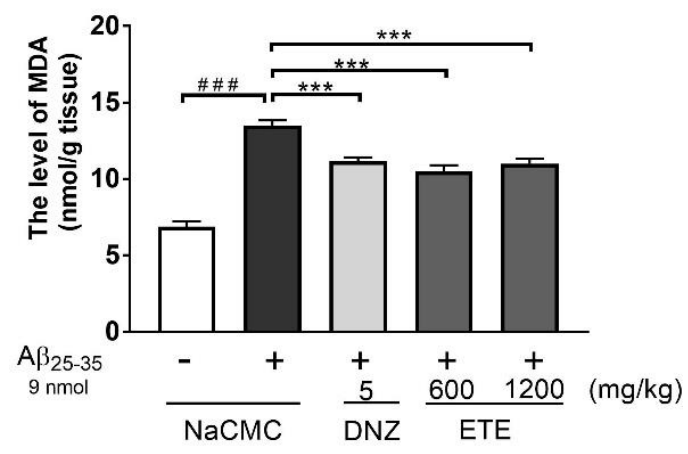

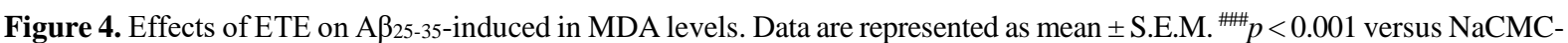
treated, distilled water-injected mice; ${ }^{* * *} p<0.001$ versus $\mathrm{NaCMC}$-treated, $\mathrm{A} \beta_{25-35}$-injected mice. $\mathrm{N}=11$ per group.

\subsection{Effects of ETE against $A \beta_{25-35}$-induced cytotoxicity}

Prior to the assessment of the neuroprotective effect of ETE, its direct effect on the cell viability of NG108-15 cells was executed. The cell viability was determined following incubating cells with various concentrations $(0.5-10 \mu \mathrm{g} / \mathrm{ml})$ of the extract in the cultured medium for $48 \mathrm{~h}$. The results as shown in Figure 5A demonstrated that cell survival was decreased in the presence of high concentrations of samples. The concentrations at $0.5 ; 1.0$ and $2.0 \mu \mathrm{g} / \mathrm{ml}$ of ETE did not affect or only slightly decreased cell viability. Therefore, these concentrations were used for later experiments.

The neuroprotective activity of ETE at different concentrations was evaluated by the viability of cells injured with $A \beta_{25-35}$ in the presence of the sample $2 \mathrm{~h}$ prior to the peptide incubation (Figure 5B). The survival rate of cells decreased to $49.38 \%$ after the incubation with 20 $\mu \mathrm{M}$ of $\mathrm{A} \beta_{25-35}$ for $48 \mathrm{~h}(p<0.001)$. Pre-treatment with ETE attenuated the $A \beta_{25-35}$-induced decrease

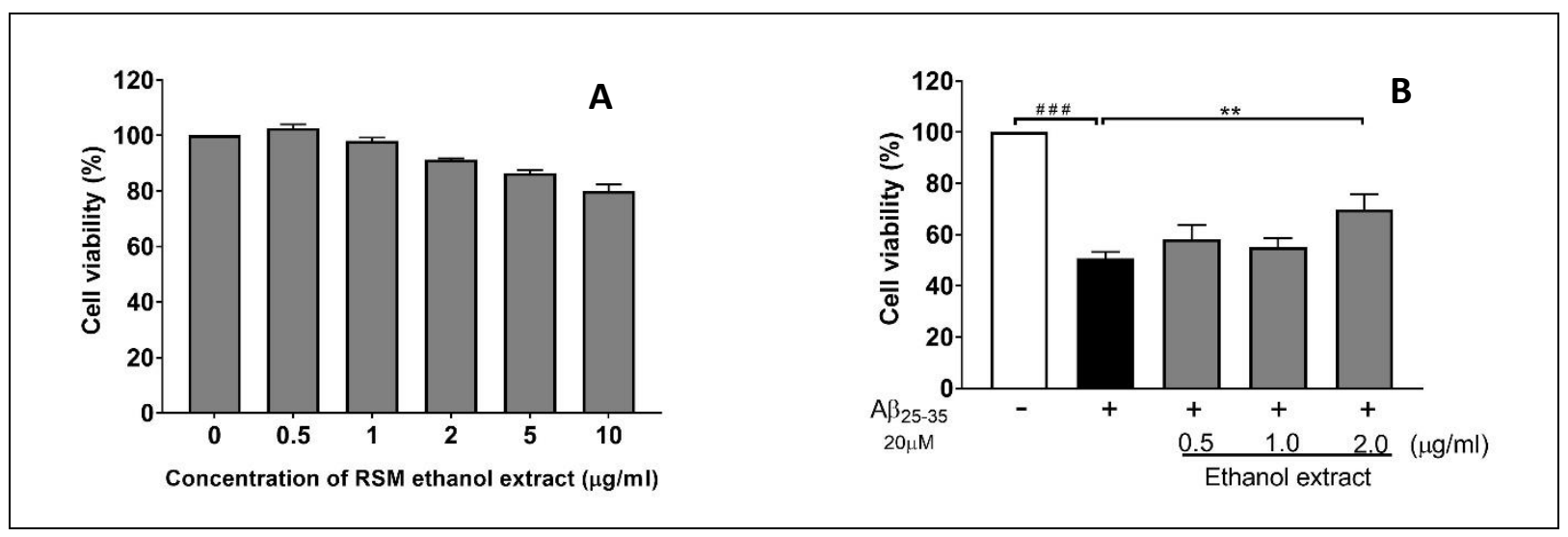

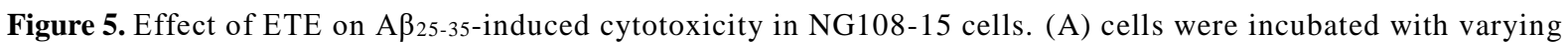
concentrations; (B) Cells were pretreated with different concentrations of the extract for $2 \mathrm{~h}$ and then incubated with or without $A \beta_{25-35}$ for an additional $48 \mathrm{~h}$. The data are represented as mean \pm S.E.M of three different experiments. ${ }^{\# \# \#} p<0.001$ versus control; ${ }^{* *} p<0.01$ versus $A \beta_{25-35}$-treated cells. 
in cell viability. However, cell viability at the ETE concentration of $2.0 \mu \mathrm{g} / \mathrm{ml}$ significantly increased $38.09 \%(p=0.002)$.

\section{DISCUSSION}

Our study evaluated whether the subchronic administration of ethanol extract $(400,600,1200 \mathrm{mg} / \mathrm{kg})$ of radix Salvia miltiorrhiza could improve $\mathrm{A} \beta_{25-35}$-induced toxicity in vitro and in vivo. We found that ETE at the doses of 600 and $1200 \mathrm{mg} / \mathrm{kg}$ prevented $A \beta_{25-35}$-induced impairments of the spontaneous alternation in Y-maze test and the latency time in passive avoidance test, but the dose of $400 \mathrm{mg} / \mathrm{kg}$ only able to improve the spontaneous alternation in Y-maze test. In addition, the oral administration of ETE at 600 and $1200 \mathrm{mg} / \mathrm{kg}$ doses could decrease the accumulation of MDA in the brain tissue homogenate containing the hippocampus and cortex as well as the treatment at $2.0 \mu \mathrm{g} / \mathrm{ml}$ of ETE inhibited $A \beta_{25-35}$-induced cell death. To our knowledge, this is the first study to indicate that ETE has the protective potential against $\mathrm{A} \beta_{25-35}$-induced neurotoxicity by regulating oxidative stress in the brain of mice.

Alzheimer's disease is a neurodegenerative disorder featuring gradually progressive cognitive and functional deficits as well as behavioral changes associated with the accumulation of amyloid in the brain ${ }^{15}$. $A \beta_{25-35}$ possesses most of the biological properties of the full length- $A \beta$ including aggregative ability and neurotoxic properties such as learning and memory impairment, oxidative stress, inflammation, neuronal loss and cell death ${ }^{4,6,16}$. In the current study, i.c.v. injection of $A \beta_{25-35}$ at $9 \mathrm{nmol}$ led to the memory impairment in both the Y-maze and passive avoidance tests. Our results are agreeable with previous observations that $A \beta_{25-35}$-induces cognitive impairment in mice ${ }^{17,18}$.

Salvia miltiorrhiza is highly valued for its roots in traditional Vietnamese medicine. After the extraction process, the ethanol extract has high contents of tanshinone IIA and salvianolic acid B. The pre-treatment with ETE prevented the i.c.v. injection of $A \beta_{25-35}$-induced deficits in short-term and long-term memory tests. In the Y-maze test, a beneficial effect was noticed when mice treated with ETE had the same spontaneous alternations as that in the control group. In the passive avoidance test, the extract also ameliorated the reductions in latency time induced by $A \beta_{25-35}$.
These results are supported by some evidence from different studies on major compounds isolated from RSM. Mei Z and Zhu J observed that tanshinone IIA (40 or $80 \mathrm{mg} / \mathrm{kg}$ ) and cryptotanshinone (5 or $10 \mathrm{mg} / \mathrm{kg}$ ) had the ability to ameliorate spatial memory deficits induced by i.c.v. injection of $A \beta_{25-35}$ in Morris water maze test ${ }^{19,20}$. Other studies have shown that the administration of salvianolic acid B (10 $\mathrm{mg} / \mathrm{kg}$ ) ameliorated $\mathrm{A} \beta_{25-35}$-induced cognitive dysfunction in the $\mathrm{Y}$-maze and passive avoidance tests $^{12,13}$. However, no pharmacological studies have been issued on the influence of the crude extracts of RSM in this model.

The mechanism responsible for the neuroprotective activity of RSM has been proposed based on the hypothesis that oxidative stress plays a critical role in the development of Alzheimer's disease. MDA is the most abundant individual aldehyde resulting from lipid peroxidation and can be considered a marker of lipid peroxidation ${ }^{21,22}$. To investigate the effect of ETE on $A \beta_{25-35}$-induced oxidative stress, we measured the levels of MDA in the brain tissue homogenate containing hippocampus and cortex. $\mathrm{A} \beta_{25-35}$ injection increased this parameter and could be considered the main culprit in lipid peroxidation. MDA accumulation induced by $\mathrm{A} \beta_{25-35}$ has been prevented by treatment with the ethanol extract. Accordingly, these results suggest that the protective effect of the ETE on $\mathrm{A} \beta_{25-35}$-induced memory impairment is related to the oxidative stress in the brain. In agreement with our results, Lee JE, et al found that salvianolic acid $B$ could attenuate $A \beta_{25-35-}$ induced lipid peroxidation ${ }^{12}$.

In vitro experiments, we further explored the mechanism underlying the protective effect of the extract against $A \beta_{25-35}$-induced neurotoxicity in NG108-15 cells. Our present study indicated that the cells were preincubated at the ETE concentration of 2.0 $\mu \mathrm{g} / \mathrm{ml}$ could improve cell viability. Previous reports also suggested that pretreatment of cells with aqueous and ethanol extract of RSM attenuated $A \beta_{25-35}$-induced cell death ${ }^{6,23}$. Furthermore, the isolated compounds from RSM such as tanshinone IIA and salvianolic acid $\mathrm{B}$ also protected against the neurotoxicity of $A \beta_{25-35}$, increased the viability of cells ${ }^{23,24}$.

In summary, our results disclosed, for the first time, that ETE could alleviate the memory deficits induced by $A \beta_{25-35}$ in mice. The effect of ETE may be attributed to the prevention of oxidative damage in the brain and protected 
against $\mathrm{A} \beta_{25-35}$-induced cytotoxicity.

\section{CONCLUSIONS}

This study provides additional evidence that the RSM ethanol extract treatment prevents the learning and memory impairment and attenuates the neurotoxicity induced by $\mathrm{A} \beta_{25-35}$. The neuroprotective effects observed in vitro and in vivo indicate that radix Salvia miltiorrhiza may offer a potential treatment option for Alzheimer's disease.

\section{Conflict of interest}

None to declared.

Funding

None to declared.

\section{Ethics approval}

Scientific and Ethical Committee of Hanoi University of Pharmacy, Vietnam (412/QD-DHN) approved the experimental protocols in this study.

\section{Article info:}

Received December 6, 2019

Received in revised form June 11, 2020

Accepted June 28, 2020

\section{REFERENCES}

1. Alzheimer's Association. Alzheimer's Association Report, 2017 Alzheimer's disease facts and figures. Alzheimer's \& Dementia. 2017;13(4):325-73.

2. Kaminsky YG, Marlatt MW, Smith MA, Kosenko EA. Subcellular and metabolic examination of amyloid-beta peptides in Alzheimer disease pathogenesis: evidence for Abeta(25-35). Exp Neurol. 2010;221(1):26-37.

3. Pike CJ, Walencewicz-Wasserman AJ, Kosmoski J, Cribbs DH, Glabe CG, Cotman CW. Structure-activity analyses of beta-amyloid peptides: contributions of the beta 25-35 region to aggregation and neurotoxicity. J Neurochem. 1995;64(1):253-65.

4. Maurice T, Lockhart BP, Privat A. Amnesia induced in mice by centrally administered beta-amyloid peptides involves cholinergic dysfunction. Brain Res. 1996;706(2):181-93.

5. Zhang XZ, Qian SS, Zhang YJ, Wang RQ. Salvia miltiorrhiza: A source for anti-Alzheimer's disease drugs. Pharm Biol. 2016;54(1):18-24.

6. Yu H, Yao L, Zhou H, Qu S, Zeng X, Zhou D, et al. Neuroprotection against Abeta25-35-induced apoptosis by Salvia miltiorrhiza extract in SH-SY5Y cells. Neurochem Int. 2014;75:89-95.

7. Fang J, Wang L, Wu T, Yang C, Gao L, Cai H, et al. Network pharmacology-based study on the mechanism of action for herbal medicines in Alzheimer treatment. J Ethnopharmacol. 2017;196:281-92.

8. Ren Y, Houghton PJ, Hider RC, Howes MJ. Novel diterpenoid acetylcholinesterase inhibitors from Salvia miltiorhiza. Planta Med. 2004;70(3):201-4.

9. Pang $\mathrm{H}, \mathrm{Wu} \mathrm{L}$, Tang $\mathrm{Y}$, Zhou G, Qu C, Duan JA. Chemical Analysis of the Herbal Medicine Salviae miltiorrhizae Radix et Rhizoma (Danshen). Molecules. 2016;21(1):51.

10. Vietnamese Pharmacopoeia Commission. Vietnamese Pharmacopoeia. Hanoi, Vietnam: Medical Publshing House; 2017.

11. Paxinos B.G. FKBJ. The Mouse Brain in Stereotaxic Coordinates. San Diego. 2004:256.

12. Lee JE, Han PL. An update of animal models of Alzheimer disease with a reevaluation of plaque depositions. Exp Neurobiol. 2013;22(2):84-95.

13. Kim DH, Park SJ, Kim JM, Jeon SJ, Kim DH, Cho YW, et al. Cognitive dysfunctions induced by a cholinergic blockade and Abeta 25-35 peptide are attenuated by salvianolic acid B. Neuropharmacology. 2011;61(8): 1432-40.

14. Wasowicz W, Neve J, Peretz A. Optimized steps in fluorometric determination of thiobarbituric acidreactive substances in serum: importance of extraction $\mathrm{pH}$ and influence of sample preservation and storage. Clin Chem. 1993;39(12):2522-6.

15. Apostolova LG. Alzheimer Disease. Continuum (Minneap Minn). 2016;22(2 Dementia):419-34.

16. Shen YX, Xu SY, Wei W, Sun XX, Liu LH, Yang J, et al. The protective effects of melatonin from oxidative damage induced by amyloid beta-peptide 25-35 in middle-aged rats. J Pineal Res. 2002;32(2):85-9.

17. Detrait ER, Danis B, Lamberty Y, Foerch P. Peripheral administration of an anti-TNF-alpha receptor fusion protein counteracts the amyloid induced elevation of hippocampal TNF-alpha levels and memory deficits in mice. Neurochem Int. 2014;72:10-3.

18. El Bitar F, Meunier J, Villard V, Almeras M, Krishnan $\mathrm{K}$, Covey DF, et al. Neuroprotection by the synthetic neurosteroid enantiomers ent-PREGS and ent-DHEAS against Abeta(2)(5)(-)(3)(5) peptide-induced toxicity in vitro and in vivo in mice. Psychopharmacology (Berl). 2014;231(17):3293-312.

19. Mei Z, Zhang F, Tao L, Zheng W, Cao Y, Wang Z, et al. Cryptotanshinone, a compound from Salvia miltiorrhiza modulates amyloid precursor protein metabolism and attenuates beta-amyloid deposition through upregulating alpha-secretase in vivo and in vitro. Neurosci Lett. 2009; 452(2):90-5.

20. Zhu J, Chen X, Song Y, Zhang Y, Zhou L, Wan L. Deficit of RACK1 contributes to the spatial memory impairment via upregulating BECLIN1 to induce autophagy. Life Sci. 2016;151:115-21.

21. Pratico D. Alzheimer's disease and oxygen radicals: new insights. Biochem Pharmacol. 2002;63(4):563-7.

22. Slater TF. Overview of methods used for detecting lipid peroxidation. Methods Enzymol. 1984;105:283-93.

23. Zhou Y, Li W, Xu L, Chen L. In Salvia miltiorrhiza, phenolic acids possess protective properties against amyloid beta-induced cytotoxicity, and tanshinones act as acetylcholinesterase inhibitors. Environ Toxicol Pharmacol. 2011;31(3):443-52.

24. Shi LL, Yang WN, Chen XL, Zhang JS, Yang PB, Hu $\mathrm{XD}$, et al. The protective effects of tanshinone IIA on neurotoxicity induced by beta-amyloid protein through calpain and the p35/Cdk5 pathway in primary cortical neurons. Neurochem Int. 2012;61(2):227-35. 